\title{
NIST STRAY LIGHT ELIMINATION TUBE PROTOTYPE
}

\section{P.A. Boynton \\ E.F. Kelley}

U.S. DEPARTMENT OF COMMERCE

Technology Administration

National Institute of Standards

and Technology

Electricity Division

Gaithersburg, MD 20899-8114 

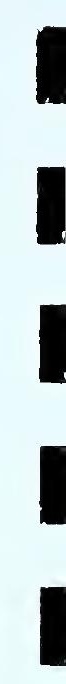


\section{NIST STRAY LIGHT ELIMINATION TUBE PROTOTYPE}

\section{P.A. Boynton \\ E.F. Kelley}

U.S. DEPARTMENT OF COMMERCE

Technology Administration

National Institute of Standards

and Technology

Electricity Division

Gaithersburg, MD 20899-8114

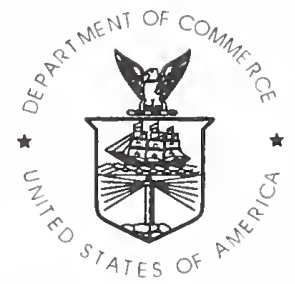

U.S. DEPARTMENT OF COMMERCE Donald L. Evans, Secretary

TECHNOLOGY ADMINISTRATION

Phillip J. Bond, Under Secretary for Technology

NATIONAL INSTITUTE OF STANDARDS

AND TECHNOLOGY

Arden L. Bement, Jr., Director 


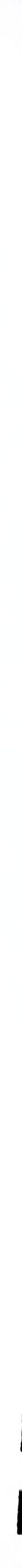




\section{NIST STRAY LIGHT ELIMINATION TUBE PROTOTYPE}

\section{Introduction}

Electronic projection displays involve the projection of an image, usually through a lens system, onto a viewing sereen. Metries such as light output. contrast, non-uniformity, and color gamut are used to describe the resultant image quality. Although standards exist that define the methodology for these measurements [1], the accuracy of measuring the light output of projection display systems can be compromised by the conditions of the viewing room. Room lights directly illuminate the screen and these light sources reflect off of walls, floors, furniture, and other objects (see Fin. 1). Additionally, backreflections from the light from the projection sereen off of objects in the room and back onto the screen must be considered. The stray-light components can contribute to the measured result, providing crroneous results.

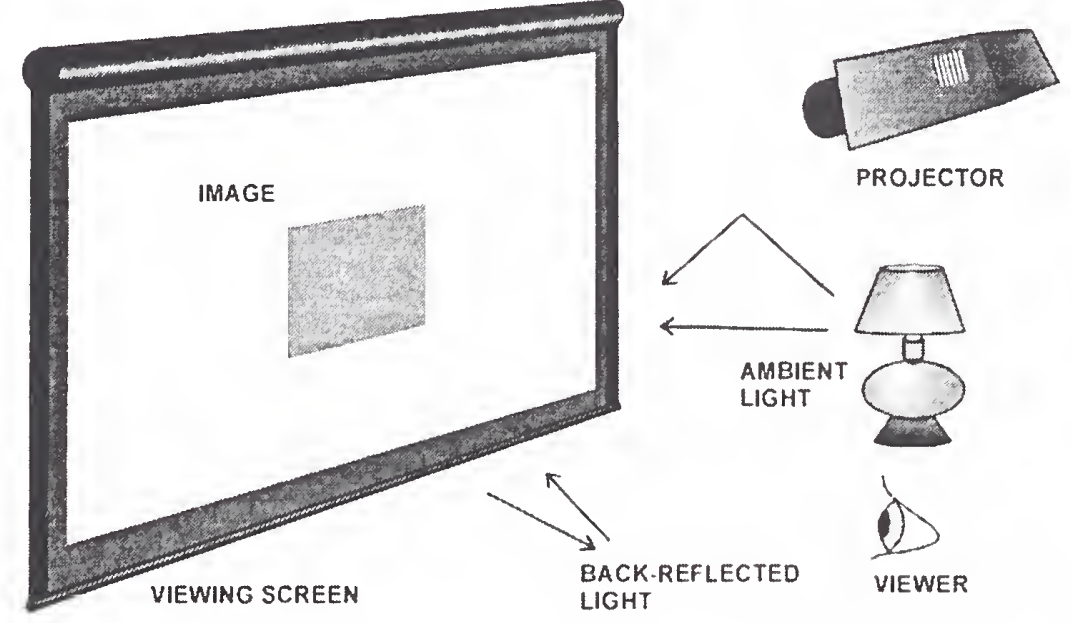

Fig. 1. Examples of stray light.

With the advent of ultralight projectors, more of these displays are being transported to a wide varicty of viewing environments. Digital cinema, home theater, business and conference use, and other applieations drive the market for large-venue projection systems. Often, they are compared to alternative or competitive technologies (within or outside of the projection display arena). These stray-light contributions can affect image quality, penalizing the projector for conditions beyond its control. In such situations, it may be important to separate out the ambient and screen effects to measure the "darkroom" projector performance [2].

A stray-light elimination tube (SLET) was developed to remove such contamination so that the user can better evaluate the performanee of the projeetion system independent of ambient light conditions [3]. This report describes the design of the first prototype SLET, developed and built in June 1998, and includes some remarks about possible improvements. 


\section{Construction}

2.1 SLET Tube. The SLET prototype consists of a $61 \mathrm{~cm}(2 \mathrm{ft})$ long piece of polyvinyl chloride (PVC) tubing" with a wall thickness o $0.64 \mathrm{~cm}(0.25 \mathrm{in}$ ) and an inner diameter of $15 \mathrm{~cm}(6 \mathrm{in})$, as shown in lïg. 2. Several frustums have been inserted to provide for the baflling and redirecting of stray light. A lengthwise section of the tube has been cut out and remounted with hinges and thumbscrews to allow acess into these interior frustums. The edges of this cutout are lined with black felt so a light-tight seal is made when closed. The entire tube is painted glossy black: the glossy paint provides for approximately $0.2 \%$ diffuse (non-specular) reflection, whereas flat black offers at best around 2-3\% diffuse refection. By careful positioning of the gloss black frustums, the S1,I:T can direct the specular reflections off the interior tube surface away fiom the illuminance meter measurement head. The back plate needs to be thin enough so that reflections off its edge do not contribute to the illuminance measurement

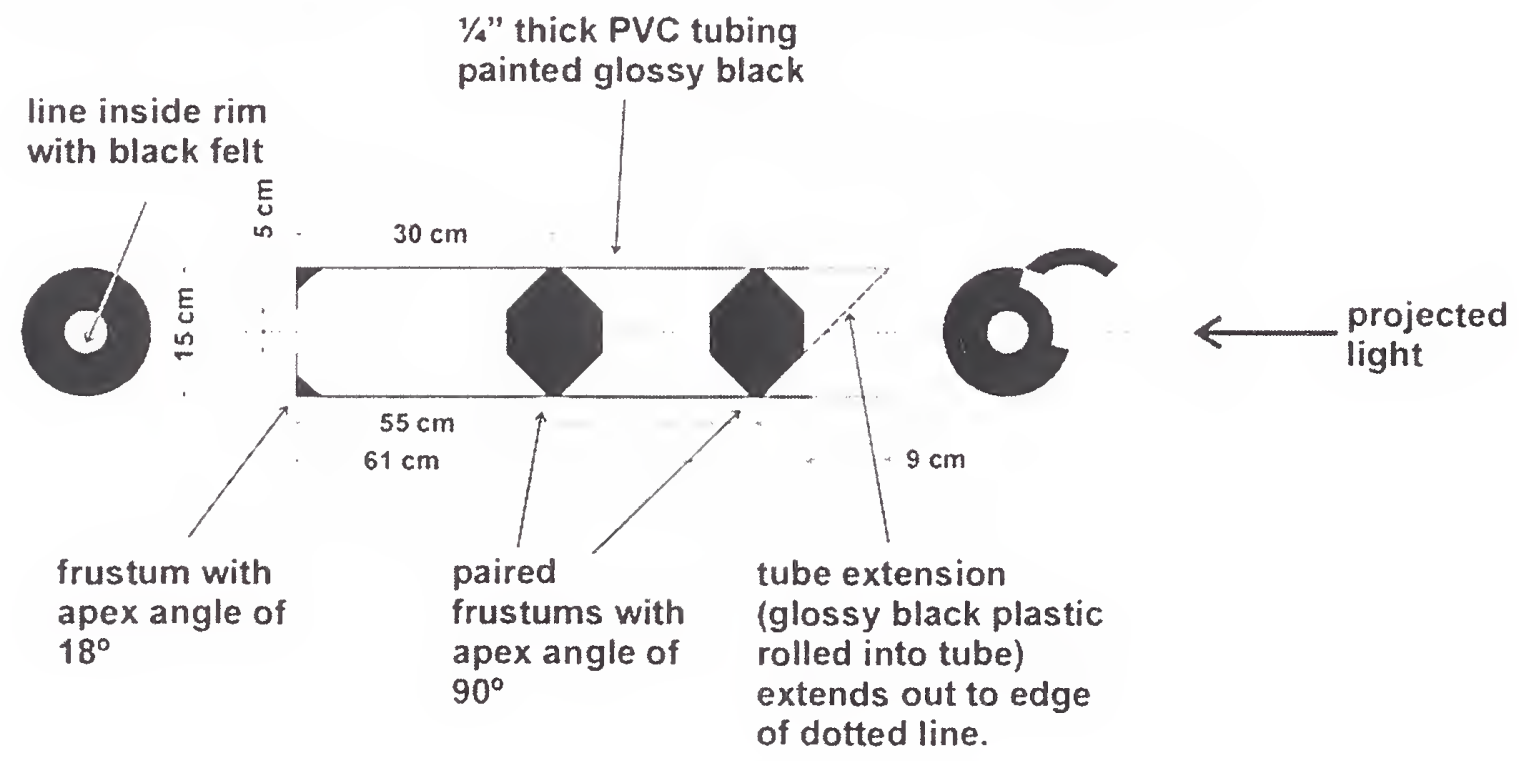

Fig. 2. Layoul of stray-light elimination tube

2.2 Frustums. Previous work corroborates the effectiveness of frustums ${ }^{*}$ as a tool in reducing the amount of stray light corrupting light-output measurements of displays [4]. The two frustum pairs have apex angles of $90^{\circ}$, with a $15 \mathrm{~cm}(6 \mathrm{in})$ exterior diameter and a $5 \mathrm{~cm}$ (2 in) inner diameter. These are positioned as shown in Fig. 2. A single frustum, mounted at the rear of the SLET tube, has an apex angle of $18^{\circ}$, with a $15 \mathrm{~cm}(6 \mathrm{in})$ exterior diameter and a $14 \mathrm{~cm}(5.5 \mathrm{in})$ inner diameter. The frustum aperture size and the placement of the pairs inside the tube were determined by performing ray tracing to determine reasonable sizes and locations (see Fig. 2).

\footnotetext{
* Common sewer drain tube can work, although a smooth interior lube should be beller for controlling reflections.
}

† Some carlier references incorrectly call them "cones." 
The frustums are construeted from 10 mil black vinyl plastic with a gloss surface on both sides, using the procedure described in Fig. 3. The equations relate the frustum apex angle and inner/outer diameters to a flat surface that can be casily cut using a mechanical compass with a sharpened edge for cutting the plastic. (Art supply or hobby stores sometimes have such compasses designed for cutting.) Place one point at the center and rotate around the center with the cutter until the material becomes separated. Also, back and forth bending along a partial eut with a little stress can separate the material. Be sure to cut out the outer diameter lirst; otherwise the center reference is lost.

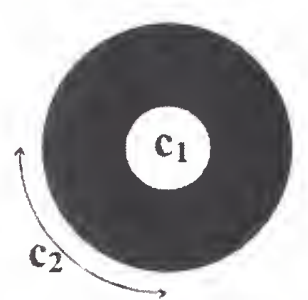

FRONT VIEW

$$
\begin{aligned}
& R=2 \phi=a p \times \text { anglt } \\
& w=R_{2}-R_{1}=\left(r_{1}-r_{2}\right) / \cos \phi \\
& C_{1}=2 \pi r_{1}=R_{1} \theta \\
& C_{2}=2 \pi r_{2}=R_{2} \theta \\
& R_{1}=r_{1} / \cos \phi \\
& R_{2}=r_{2} / \cos \phi \\
& 0=2 \pi \cos \phi \\
& \text { lor } \phi=45^{\circ}, \cos \phi=\frac{1}{\sqrt{2}} \\
& R_{1}-\sqrt{2} r_{1} \\
& R_{2} \sqrt{2} r_{2} \\
& 0=\pi \sqrt{2}
\end{aligned}
$$

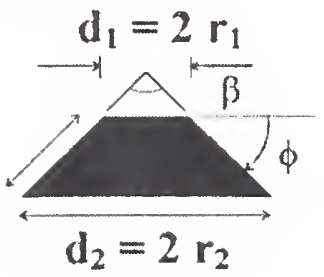

SIDE VIEW

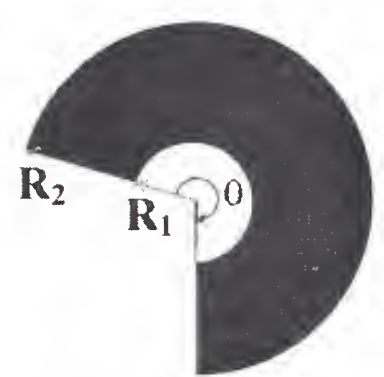

CUT FROM FLAT SHEET

Fig. 3. Frustum construction parameters.

2.3 Frustum Rings. The frustums are inserted into the tube by attaching each pair to a $0.64 \mathrm{~cm}$ (0.25 in) thick ring, as shown in Fig. 4. The rings, which are made out of PVC or black acetal plastic (and painted gloss black), have an outer diameter of slightly less that the inner diameter of the tube (to accommodate the tabs and felt). For the prototype, the outer diameter is slightly less than $15 \mathrm{~cm}(6 \mathrm{in})$ so as to fit snugly in the tube and have an inner diameter of $11.4 \mathrm{~cm}$ (4.5 in). 'labs hold the frustums in place and are constructed from the same thin plastic material as the frustums. The tabs are cut and shaped so that the frustums will not dislodge when tilting the tube. Black felt is applied with double-stick tape around the edge of the ring to prevent light leakage (see Fig. 5).

\section{Design Considerations}

The SLET prototype described was built for the International Communications Industries Association (ICIA) InfoComm Projection Display Shoot-Out in June 1998 in Dallas, TX, to evaluate the effect of ambient light on measurements being made during the 


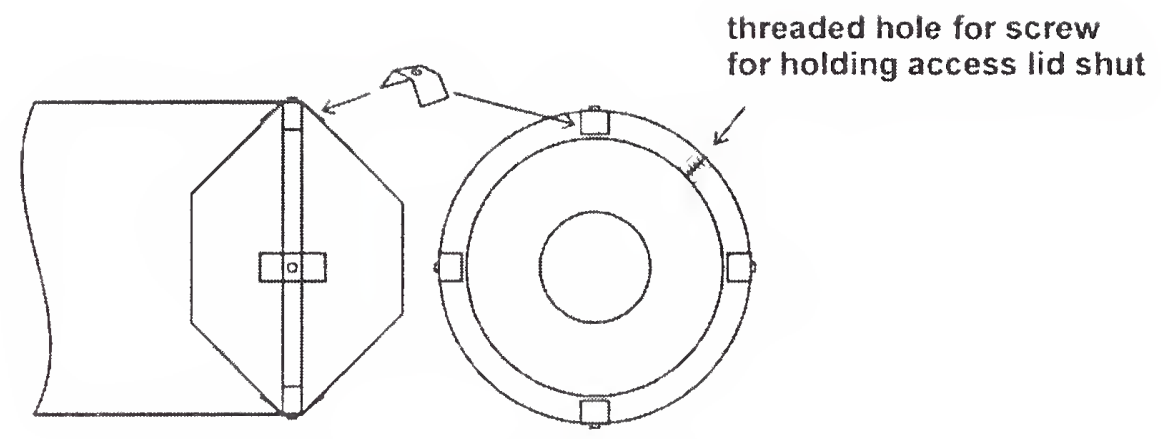

Fig. 4. Frustum rings.

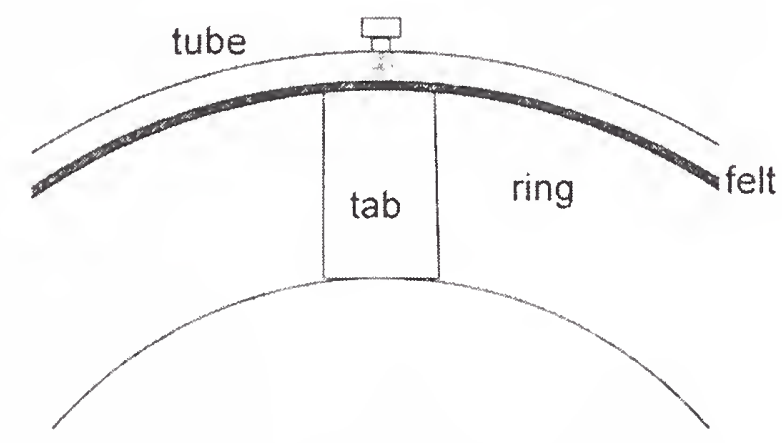

Fig. 5. Detail of frustum rings.

exhibition [5]. The SLET was constructed for ruggedness and effectiveness, not necessarily for portability.

Recently, more portable designs have been shown to be equally effective. Using the same gloss black material as the frustums, one can construct a tube as shown in Fig. 6. Three black acetyl plastic rings, similar to the prototype design, are used to provide a rigid structure in which to secure the tube. One ring should be designed for proper mounting of the illuminance meter. Different mounting rings can be built and easily

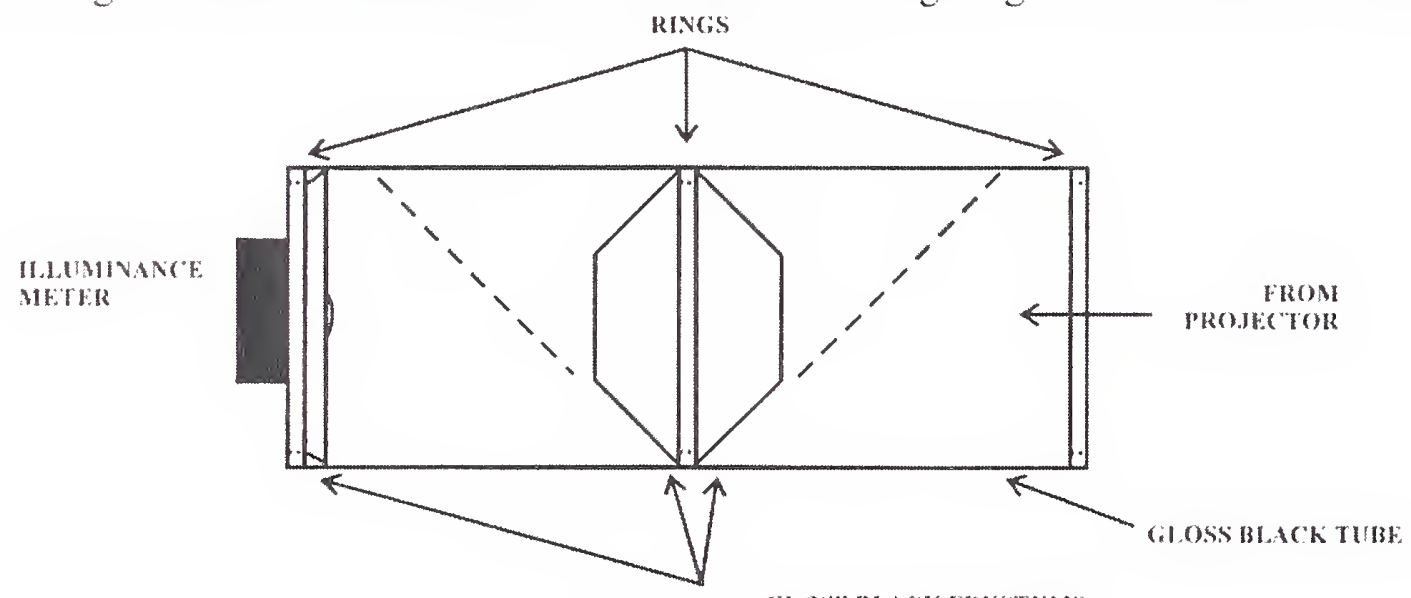

GLOSS BLACK RUUSTUMS

Fig. 6. Portable SLET. 
inserted to hold various types of illuminance meters. (Other rings keep the frustums in place. The inner diameter of the ring that aecommodates the illuminanee meter must be thin enough to not reflect any light onto the illuminance meter.

\section{Operation}

To perform illuminance measurements on front-projection displays, be sure the SLET is aligned correctly. Aim the tube toward the projector source as demonstrated in lig 7. Mounting the SLET onto a tripod may ease use and improve stability of alignment. Use the shadow of the tube aperture (with the illuminance meter removed) imaged onto the screen as an alignment guide. Be sure there are no stray-light sources directly near the SLET field of view in the direction of the projector.

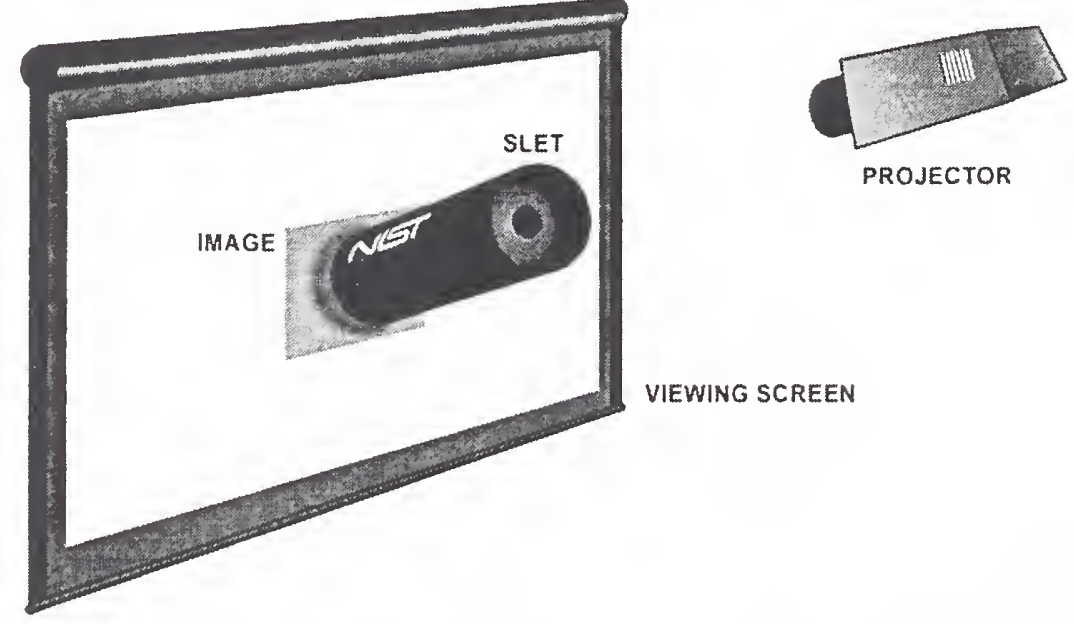

Fig. 7. Using the SLET for front-projection display measurements.

For rear-projection systems and other direct-view emissive displays, the SLET can be conligured into a "portable darkroom." $\wedge$ s illustrated in Fig. 8, a SLET maly be placed up near the screen. The front edge of the SLET tube needs to be covered with black felt or other protective material to reduee light leakage around the instrument. Furthermore, to prevent stray light from striking and subsequently internally reflecting within the screen, the screen can be cloaked with black felt or other light-blocking material with low reflectance properties.

For performing small-area illuminance measurements at the position of the screen, a slit adapter can be used [6]. The one pictured in Fig. 9 was built using black acetal plastic to mount the illuminance meter, so that various detector heads could be centered at the rear of the SLET. To accommodate the small measurement areas, a slit, using razor blades painted in glossy black, was devised to create an adjustable aperture. The blades are secured with set screws to provide for adjustment. This allows the user to control the area of the projected image to be measured. Thus, one could measure contrast modulation by adjusting the aperture to allow only either the black or the white portion of the image to illuminate the detector head. 


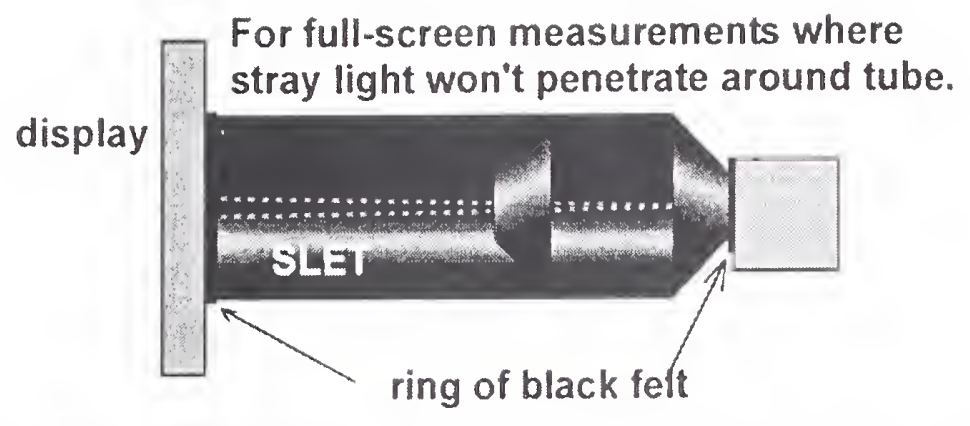

For smaller area measurements

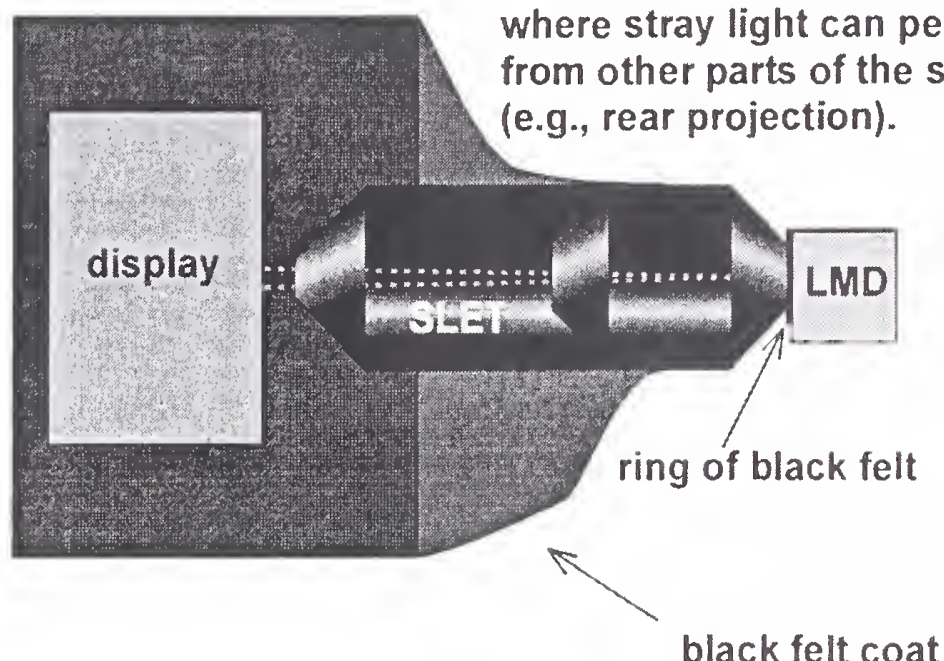

Fig. 8. Using a portable-darkroom SLET for small-area measurements.

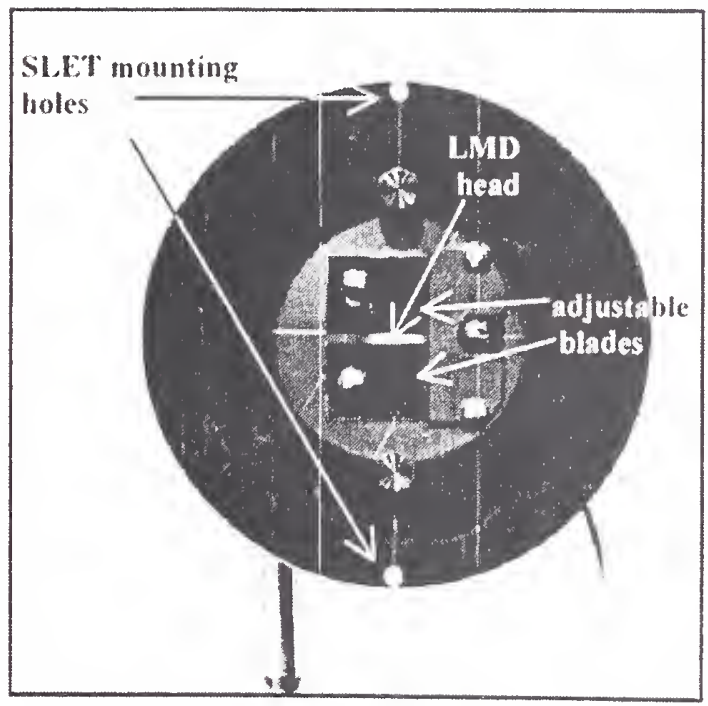

Fig. 9. Slit adapter for illuminance meters. 


\section{Summary}

In order to separate out stray light from the measurement of projector performance, the SLET can be a simple but effective tool. We have used both this prototype and a more portable design to improve accuracy in several special situations $[5,7,8]$ as well as in our routine laboratory work. In all of these cases, using the SI.ET has determined the ambient contributions to the projected image and provided for stray-light reduction so that projectors could be more accurately characterized.

\section{REFERENCES}

I. For example, see ANSI/NAPM IT7.228-1997 Electronic Projection-Fixed Resolution Projectors, ANSI/PIMA IT7.227-I998 Electronic Projection-Variable Resolution Projectors, IEC Draft 61947-1 Ed. 1.0 and IEC Draft 61947-2 Ed. I.0.

2. P. A. Boynton and E. F. Kelley, "Compensation for Stray Light in Projection Display Metrology," Society for Information Display International Symposium Digest of Technical Papers, San Jose, CA, June 3-8, 2001, Vol. XXXII, pp. 334-337 (June $2001)$.

3. P. A. Boynton and F. F. Kelley, "Stray Light Elimination in Making Projection Display Measurements," Flat F'anel Display Techology and Display Metrology, Proceedings of the SPIE, Vol. 3636, pp. 232-239 (1999).

4. P. A. Boynton and E. F. Kelley, "Accurate Contrast Ratio Measurements Using a Cone Mask," Society for Information Display International Symposium Digest of Technical Papers. Boston, MA, May I1-16, 1997. Vol. XXV1HI, pp. 823-826 (May 1997).

5. "NIST Development Contributes to Sucecss of Display "Shoot-Out", NIST Monthly llighlights, September 1998.

6. P. Boynton and E. Kelley, "Stray Light Compensation in Small Area Contrast Measurements of Projection Displays," Projection Displays VIII, Proceedings of the SPIE, Vol. 4657 (2002).

7. "NIST Assists in the Development of an ICIA Pilot Projection Display Livaluation Program," NIST Monthly Ilighlights, July 1999.

8. P. Boynton and C. Fenimore, "Characterization of Projection Systems for the MPEG4 Digital Cinema Compression Scheme Evaluation," NISTIR 6792, (September 2001). 


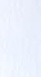




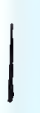

I

I

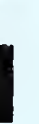

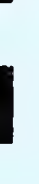


